Sharif University of Technology
Scientia Iranica
Transactions E: Industrial Engineering
SCIENTIA

\title{
A mathematical model for competitive location problem with product selection
}

\author{
S.J. Sadjadia ${ }^{a, *}$, M. Gorji Ashtiani ${ }^{a}$, A. Makui ${ }^{a}$, and R. Ramezanian ${ }^{b}$ \\ a. Department of Industrial Engineering, Iran University of Science and Technology, Narmak, Tehran, Iran. \\ b. Department of Industrial Engineering, K. N. Toosi University of Technology, Vanak, Tehran, Iran. \\ Received 13 September 2018; received in revised form 16 October 2018; accepted 8 December 2018
}

\author{
KEYWORDS \\ Competitive location; \\ Product variety; \\ Huff rule; \\ Mixed integer linear \\ programming; \\ Location-product; \\ Hybrid heuristic- \\ firefly algorithm.
}

\begin{abstract}
In this paper, a new competitive location problem for a chain is considered. The owner of the chain can offer a variety of products. The objective of the model is to determine both the location of new facilities and the optimal product type for each opened facility. The patronizing behavior of the customers is based on Huff rule and the location of new facilities is selected from a set of potential sites. As a result, the proposed model is a nonlinear integer programming problem and for solving it, the problem is reformulated as a mixed integer linear programming one. Therefore, a standard optimization solver can be used for obtaining the optimal solutions to small- and medium-size problems. To cope with large-size problems, we develop two methods: 1) a heuristic method for a special case and 2) a hybrid heuristic-firefly algorithm for general cases. By using the proposed model, it is numerically shown that in multi-product industries in which the owner of the facilities is able to offer different types of products, in addition to the optimal location, it is necessary to determine the best products. At the end, a real-world case study for locating a new bakery is presented.

(C) 2020 Sharif University of Technology. All rights reserved.
\end{abstract}

\section{Introduction}

Facility location is a critical part of strategic planning for different firms, because location decisions are costly and difficult to reverse and their impact spans a longtime horizon [1]. Location problem has different types. For example, covering location [2] and hub location [3] are some of the well-known problems in this field. The readers who are interested in learning about different location models are referred to the survey papers $[1,4,5]$.

Competitive Facility Location (CFL) problems

\footnotetext{
*. Corresponding author. Tel.: +98 77240129, +98 73225027 E-mail addresses: sjsadjadi@iust.ac.ir (S.J. Sadjadi); M_Gorji_Ashtiani@ind.iust.ac.ir (M. Gorji Ashtiani); amakui@iust.ac.ir (A. Makui); Ramezanian@kntu.ac.ir (R. Ramezanian)
}

doi: $10.24200 /$ sci. 2018.51736 .2337 have propelled the classical location models to a more complicated situation in which different owners of facilities compete for increasing their market shares. In such circumstances, different preferences of customers, possible reactions of competitors, and many other factors should be noticed. Early studies of the CFL problems were carried out by Hotelling [6], Hakimi [710], Drezner [11], and Huff $[12,13]$. There are at least four papers reviewing the literature on CFL models [14-17].

\subsection{Literature review}

The differences of CFL models stem from their different types of components. For example, the space for locating new facilities can be plane, network, or discrete; the type of competition can be considered static, with foresight, or dynamic; and depending on whether the product is necessary or not, the demand can be elastic or inelastic. One of the other important issues 
Table 1. Categorization of the Competitive Facility Location (CFL) papers published from 2000 to 2018.

\begin{tabular}{cccc}
\hline $\begin{array}{c}\text { Patronizing behavior } \\
\text { \& variables }\end{array}$ & $\begin{array}{c}\text { Location and } \\
\text { design }\end{array}$ & $\begin{array}{c}\text { Location and } \\
\text { price }\end{array}$ & $\begin{array}{c}\text { Location and } \\
\text { other variables }\end{array}$ \\
\hline Deterministic & {$[19-23]$} & {$[47-55]$} & {$[57-59]$} \\
Probabilistic & {$[24-46]$} & {$[56]$} & {$[60]$} \\
\hline
\end{tabular}

Table 2. Selected researches and classification.

\begin{tabular}{cccccc}
\hline \multirow{2}{*}{ Research } & \multicolumn{3}{c}{ Model variables } & \multicolumn{2}{c}{ Patronizing behavior } \\
\cline { 2 - 5 } & Location & Price & Product & Deterministic & Probabilistic \\
\hline$[54]$ & $\sqrt{ }$ & $\sqrt{ }$ & $\times$ & \\
{$[55]$} & $\sqrt{ }$ & $\sqrt{ }$ & $\times$ & \\
{$[65]$} & $\sqrt{ }$ & $\sqrt{ }$ & & $\times$ \\
{$[66]$} & & $\sqrt{ }$ & $\sqrt{ }$ & $\times$ \\
\hline
\end{tabular}

in the CFL problems is the patronizing behavior of the customers. In some problems, the choice of customers is based on the deterministic rule. That is, the demand of all customers is provided by the facility that has attracted the greatest interest. In another case, the customers divide their demands among various facilities based on a probabilistic approach.

Another difference of the CFL models pertains to their decision variables. In many problems, the only decision variable is location (see, for instance, [18]), while some others consider other variables in addition to "location." One of the most frequently noted variables is the "design" of new facilities (see, for instance, [19]) and the problems that deal with this kind of variables are called "Location-Design" models. In Table 1, an overview of recently published papers on CFL with more than one variable in their modeling is given.

One of the underlying assumptions considered in the majority of CFL models is uniqueness of the product (or service) that is offered by the facilities and, in fact, there is no difference between various products. Hence, it is assumed that the demand is only for one product, while a variety of products can be offered by the facilities.

Serious analysis of product variety has recently been conducted in the economics literature, while it has not yet been taken seriously in CFL models. Lancaster [61] separated the product variety problems into three categories:

1. Those concentrated on the production part and the cost benefits of joint production (see, for instance, [62]);

2. Those concentrated on the demand part, highlighting the balance between the possible increased revenue from multi-product production and the loss of economies of scale for producing each individual product (see, for instance, [63]);
3. Those concentrated on the strategic considerations (see, for instance, $[54,55,64-66]$ ).

The first and the second categories investigated the impact of product diversity on production and demand variables. In this paper, we focus on the third category considering the fact that locational decisions are part of strategic planning. Although the economics literature is full of works that consider product variety in the strategic considerations (see, for instance, [64]), few researchers have considered it in CFL models. Table 2 lists the multi-product CFL studies and classifies them in terms of model variables and patronizing behavior.

The papers $[54,55,65]$ investigated both the optimal location of the new facilities and the optimal price of various products. The reason that we mention them is that they have paid attention to the multi-product concept although they have considered product type as a decision variable. Beresnev and Suslov [66] proposed a model in which both product types and their prices were considered.

As can be seen in Table 2, no work has been carried out to determine the optimal location and product, simultaneously, especially with probabilistic patronizing behavior.

\subsection{The contribution of this paper}

In some situations or environments, different types of products can be offered and delivered by a facility. Depending on which product is to be offered, the optimal location of the facility is affected. For example, suppose a bakery owner can produce three different kinds of breads, but the equipment and methods of production for each bread are different. Given the fact that each bread has its own market and customers, the new optimal facility location can vary depending on which bread to choose for production. Therefore, in this paper, we add a new decision variable to the 
competitive location problems, which is the optimal product types offered by each new facility. We show that this variable has a great impact on the location variable and vice versa. It is shown numerically that in industries where multiple products can be produced, both variables must be considered simultaneously.

A vast majority of the models in the literature do not consider the variety of products and in very limited cases, multiple products are addressed and product selection is not taken as a decision variable (except [66]). In the only work in which product selection is considered as a variable [66], location is not part of the problem variables. Therefore, to the best of the authors' knowledge, this paper is the first work in the field of competitive location to consider the optimal location and the product, simultaneously. We call this problem a "Location-Product" model.

The rest of the paper is structured as follows. The proposed model is described in Section 2. Section 3 presents the solution methods. The computational experiments are provided in Section 4 and Section 5 presents the conclusion and recommendations for future research.

\section{The proposed model}

Consider a competitive market where $p$ products or $p$ different types of one product group (such as food or bread) are offered by different competitors. These competitors have already opened up facilities at the market in which they may offer one or more types of these $p$ products. At present, there are $m$ existing facilities in which $f$ of them belong to the chain and the remaining ones belong to the competitors.
There are $n$ customers in this market and each customer may face different demands for different products, where the demand of customer $j$ for the product $t$ is $b_{j t}$. The products are assumed to be necessary and therefore, the demand is inelastic. Thus, the demands of all the customers are met by the existing facilities. When a new facility enters the market for offering a given product, some parts of the market share of the existing facilities will be cannibalized. The patronizing behavior of the customers is considered according to Huff rule. In this rule, attraction of a given customer to a facility is determined by the facility quality (design) divided by the distance (or a function of distance) between them. Obviously, the more the attraction to one facility, the higher the probability of attracting the customers by the mentioned facility. The quality parameters of a given facility for a specific product include a variety of components such as product quality, the size of facility, the number of personnel, the queue created for product receipt, the cleanliness of the facility, the availability of the park, the access to facility, the behavior of the personnel toward the customers, etc.

In this competitive market, the chain wants to open $r$ new facilities (among $o$ potential locations) and select the best product types for each opened facility. The maximum number of new facilities that offer product $t$ is $N P_{t}$. Also, since it is not possible that the potential sites (in terms of the size of the facility) offer an equal number of products, $N F_{k}$ is the maximum number of products that can be offered at potential location $k$.

As we can observe from the example shown in Figure 1 , there are 25 customers who have various buying

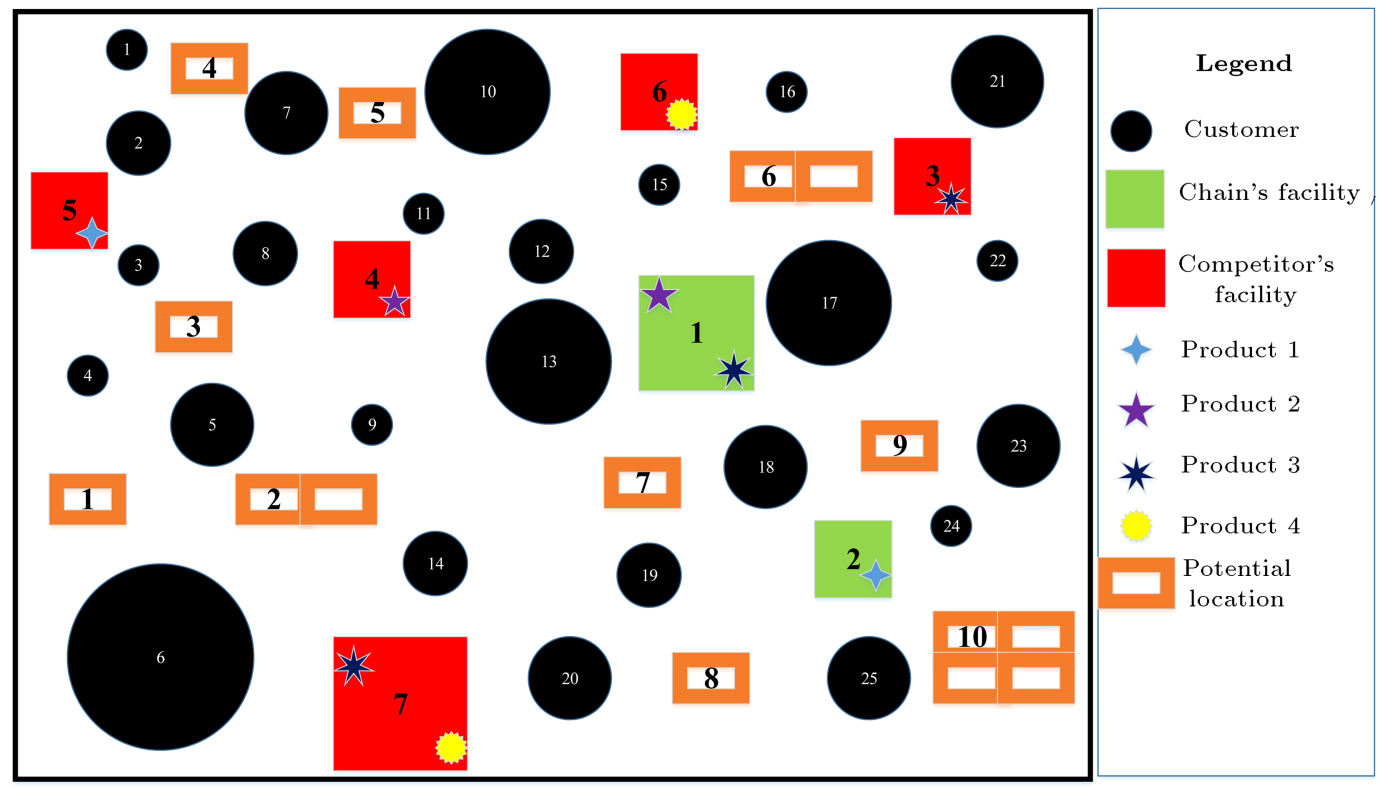

Figure 1. Illustration figure of the proposed model. 
power and therefore, their sizes are different. The chain has two existing facilities while other competitors have five existing facilities. There are four different product types available in these existing facilities. Facilities 1 and 7 deliver two products and the other facilities offer one product. There are 10 potential locations for new facilities and their sizes are different. Therefore, the number of products offered by each potential facility can vary.

The chain seeks to find answers to the following two questions:

1. What are the optimal locations of new facilities?

2. In each opened facility, which type of products should be offered? follows:

The notation used in the proposed model is as

\section{Indices}

$i \quad$ Index of existing facilities; $i=1,2, \ldots, f$ existing facilities of the chain and $i=f+1, f+2, \ldots, m$ existing facilities of the competitors

$j \quad$ Index of customers; $j=1,2, \ldots, n$

$k$ Index of potential locations; $k=$ $1,2, \ldots, o$

$t \quad$ Index of products; $t=1,2, \ldots, p$

\section{Parameters}

$m \quad$ Number of existing facilities

$n \quad$ Number of customers

$o \quad$ Number of potential locations

$p \quad$ Number of products

$b_{j t} \quad$ Demand of customer $j$ for product $t$

$d_{i j} \quad$ Distance between existing facility $i$ and customer $j$

$d_{k j} \quad$ Distance between the new facility opened at potential location $k$ and customer $j$

$\gamma_{j} \quad$ Weight for the quality of the new facilities as perceived by customer $j$

$\alpha_{i t} \quad$ Quality of product $t$ at existing facility $i$

$q_{k t} \quad$ Quality of product $t$ at new facility at potential location $k$

$p r_{t} \quad$ Profit per unit of product $t$ sold

$r \quad$ Number of new facilities

$N P_{t} \quad$ Maximum number of new facilities that offer product $t$

$N F_{k} \quad$ Maximum number of products to be delivered at potential location $k$

\section{Variables}

$y_{k} \quad$ A binary variable equal to 1 if a new facility is opened at potential location $k$ and 0 otherwise

$x_{k t} \quad$ A binary variable equal to 1 if product $t$ is produced at the new facility opened at potential location $k$ and 0 otherwise

Based on Huff rule, the attraction of customer $j$ to product $t$ at facility $i$ can be as follows [67]:

$$
U_{i j t}=\alpha_{i t} \gamma_{j} /\left(\varepsilon+d_{i j}^{2}\right) \text {. }
$$

The attraction of new facilities is calculated by Eq. (1). As mentioned before, the demand for each customer is spread across all facilities. That is, each facility meets a part of the demand of a given customer that is directly related to its attraction. Therefore, the greater the attraction of a given customer to a facility, the greater the share of the facility from the demand of the customer. If this share is considered by dividing the attraction of the customer to the facility by the overall attraction of the facilities, then the share of the chain from the demand of a particular customer equals the total attraction of the facilities of the chain (existing and new) divided by the attraction of all facilities $[12,13,26,44,67]$. Therefore, market share of the chain from the demand of customer $j$ for product $t$ can be as follows:

$$
M S_{j t}=\frac{\sum_{i=1}^{f} U_{i j t}+\sum_{k=1}^{o} U_{k j t} x_{k t}}{\sum_{i=1}^{m} U_{i j t}+\sum_{k=1}^{o} U_{k j t} x_{k t}} .
$$

The profit of the chain is equal to the total sales of products multiplied by the profit of each unit sold. Thus, the "Location-Product" problem (P1) is as follows:

$$
\operatorname{Max} z=\sum_{t=1}^{p} \sum_{j=1}^{n} \operatorname{Pr}_{t} b_{j t} \frac{\sum_{i=1}^{f} \frac{\alpha_{i t} \gamma_{j}}{\left(\varepsilon+d_{i j}^{2}\right)}+\sum_{k=1}^{o} \frac{q_{k t} \gamma_{j}}{\left(\varepsilon+d_{k j}^{2}\right)} x_{k t}}{\sum_{i=1}^{m} \frac{\alpha_{i t} \gamma_{j}}{\left(\varepsilon+d_{i j}^{2}\right)}+\sum_{k=1}^{o} \frac{q_{k t} \gamma_{j}}{\left(\varepsilon+d_{k j}^{2}\right)} x_{k t}}
$$

S.t.

$$
\begin{aligned}
& \sum_{k=1}^{o} y_{k}=r, \\
& \sum_{k=1}^{o} x_{k t} \leq N P_{t} \quad t=1,2, \ldots, p \\
& \sum_{t=1}^{p} x_{k t} \leq N F_{k} \quad k=1,2, \ldots, o \\
& y_{k} \geq x_{k t} \quad t=1,2, \ldots, p \text { and } k=1,2, \ldots, o,
\end{aligned}
$$




$$
x_{k t}, y_{k} \in\{0,1\} \quad t=1,2, \ldots, p \text { and } k=1,2, \ldots, o
$$

where Eq. (3) represents profit of the chain, which must be maximized. The number of new facilities is determined by Constraint (4) and Eq. (5) ensures that the maximum number of new facilities that offer product $t$ is equal to $N P_{t}$. Relation (6) shows how many products can be offered in each potential location. By Constraint (7) we can make sure that the products can be offered only if the facility is opened up.

This model is an integer nonlinear programming problem in which the objective function is a sum of ratios with a particular structure: Numerators and denominators of a ratio differ only by the constants. Similar problems with a sum of ratios as objective have been studied by Hansen et al. [68] and Benati and Hansen [69]. Benati [70] proved that the problem was NP-hard. In the following, we will see that the "Location-Product" problem can be reformulated into a Mixed Integer Linear Programming (MILP) problem and hence, the optimal solutions can be obtained using standard optimization software (like CPLEX, Gurobi, Mosek, Xpress-MP, etc.).

\section{Solution methods}

In this section, we introduce three solution methods for problem P1. The first one directly exploits the formulation given above. The other two methods are heuristics.

\subsection{Reformulation of the model into a MILP problem}

Let $A_{j t}=\sum_{i=1}^{f} \frac{\alpha_{i t} \gamma_{j}}{\left(\varepsilon+d_{i j}^{2}\right)}$ and $A_{j t}^{\prime}=\sum_{i=1}^{m} \frac{\alpha_{i t} \gamma_{j}}{\left(\varepsilon+d_{i j}^{2}\right)}$ for $j=$ $1,2, \ldots, n$ and $k=1,2, \ldots, o$; and $B_{j k t}=\frac{q_{k t} \gamma_{j}}{\left(\varepsilon+d_{k j}^{2}\right)}$ for $j=1,2, \ldots, n, t=1,2, \ldots, p$, and $k=1,2, \ldots, o$. The objective function can be expressed as follows:

$$
\sum_{t=1}^{p} \sum_{j=1}^{n} \operatorname{Pr}_{t} b_{j t} \frac{A_{j t}+\sum_{k=1}^{o} B_{j k t} x_{k t}}{A^{\prime}{ }_{j t}+\sum_{k=1}^{o} B_{j k t} x_{k t}} .
$$

\subsubsection{Concavity of the objective function}

Theorem 1. The continuous relaxation of the objective function $\mathbf{P} \mathbf{1}$ is concave.

Proof. Since there are existing facilities in the market, therefore $A_{j t}^{\prime}$, the attraction of the existing facilities, is definitely not equal to zero. Hence, the function does not have singularity points over the domain of its continuous relaxation and the second cross-derivative can be computed by standard methods. Since the objective function is a sum of ratios, it is sufficient to prove that each term is concave. Consider the term $j t$ :

$$
f\left(x_{1}, x_{2}, \ldots, x_{n}\right)=\operatorname{Pr}_{t} b_{j t} \frac{A_{j t}+\sum_{k=1}^{o} B_{j k t} x_{k t}}{A^{\prime}{ }_{j t}+\sum_{k=1}^{o} B_{j k t} x_{k t}},
$$

The Hessian matrix is $H=\left[h_{l w}\right]$, where:

$$
\begin{aligned}
h_{l w} & =\frac{\partial f\left(x_{1}, x_{2}, \ldots, x_{n}\right)}{\partial x_{l} \partial x_{w}} \\
& =-2 \operatorname{Pr}_{t} b_{j t} B_{j l t} B_{j w t} \frac{A^{\prime}{ }_{j t}-A_{j t}}{\left(A^{\prime}{ }_{j t}+\sum_{k=1}^{o} B_{j k t} x_{k t}\right)^{3}} .
\end{aligned}
$$

Since $A_{j t}^{\prime}-A_{j t} \geq 0, h_{l w}$ is always negative. It can be seen obviously that the determinant of every submatrix of order two is equal to 0 , while the elements on the diagonal are negative. Thus, $f\left(x_{1}, x_{2}, \ldots, x_{n}\right)$ is concave.

Note that continuous relaxation of the domain is a convex set, so an upper bound can be computed by unconstrained nonlinear optimization algorithms like gradient methods.

\subsubsection{Integer linear formulation}

Consider variable $Z_{j t}$ as follows:

$$
Z_{j t}=\frac{A_{j t}+\sum_{k=1}^{o} B_{j k t} x_{k t}}{A^{\prime}{ }_{j t}+\sum_{k=1}^{o} B_{j k t} x_{k t}} .
$$

As the denominator is positive, it is equivalent to:

$$
Z_{j t}\left(A^{\prime}{ }_{j t}+\sum_{k=1}^{o} B_{j k t} x_{k t}\right)=A_{j t}+\sum_{k=1}^{o} B_{j k t} x_{k t} .
$$

Assume the following variable:

$$
w_{j k t}=Z_{j t} x_{k t} .
$$

for which the following constraints are equivalent:

$$
w_{j k t} \leq x_{k t}
$$

and:

$$
w_{j k t} \geq Z_{j t}-\left(1-x_{k t}\right) .
$$

With these substitutions, we can write:

$$
Z_{j t} A_{j t}^{\prime}+\sum_{k=1}^{o} B_{j k t} w_{j k t}-A_{j t}-\sum_{k=1}^{o} B_{j k t} x_{k t}=0
$$

where:

$$
Z_{j t}=\frac{1}{A^{\prime}{ }_{j t}}\left(\sum_{k=1}^{o} B_{j k t} x_{k t}-\sum_{k=1}^{o} B_{j k t} w_{j k t}+A_{j t}\right)
$$


Finally, Problem P1 can be reformulated into problem P2 as follows:

$$
\begin{aligned}
& \operatorname{Max} z=\sum_{t=1}^{p} \sum_{j=1}^{n} \frac{\operatorname{Pr}_{t} b_{j t}}{A^{\prime}{ }_{j t}}\left(\sum_{k=1}^{o} B_{j k t} x_{k t}-\sum_{k=1}^{o} B_{j k t} w_{j k t}\right. \\
& \left.\quad+A_{j t}\right)
\end{aligned}
$$

S.t.

$$
\begin{aligned}
& w_{j k t} \geq \frac{1}{A_{j t}^{\prime}}\left(\sum_{k^{\prime}=1}^{o} B_{j k^{\prime} t} x_{k^{\prime} t}-\sum_{k^{\prime}=1}^{o} B_{j k^{\prime} t} w_{j k^{\prime} t}+A_{j t}\right) \\
& -\left(1-x_{k t}\right) \\
& j=1,2, \ldots, n ; t=1,2, \ldots, p, \quad \text { and } k=1,2, \ldots, o, \\
& \sum_{k=1}^{o} y_{k}=r \\
& \sum_{k=1}^{o} x_{k t} \leq N P_{t} \quad t=1,2, \ldots, p \\
& \sum_{t=1}^{p} x_{k t} \leq N F_{k} \quad k=1,2, \ldots, o \\
& y_{k} \geq x_{k t} \quad t=1,2, \ldots, p \text { and } k=1,2, \ldots, o \\
& x_{k t}, y_{k} \in\{0,1\} \text { and } w_{j k t} \geq 0 \\
& j=1,2, \ldots, n ; t=1,2, \ldots, p \text { and } k=1,2, \ldots, o \text {. }
\end{aligned}
$$

As $w_{j k t} \leq x_{k t}$ is a redundant constraint, it can be removed from the model. This formulation is a MILP formulation and therefore, the optimal solution can be obtained by a standard Mixed Integer Programming (MIP) solver.

\subsection{A heuristic method (for a special case)}

Since the problem is NP-hard, heuristic methods must be used for large-scale problems. In this section, we present a heuristic method for a special case of $\mathbf{P} \mathbf{1}$. The case occurs when the right-hand side of Constraint (6) is equal to 1 . That is, only one product can be offered by each potential location. Since the facilities usually have a space limitation in practice, this assumption is not unrealistic and the mentioned case is applicable to many situations.

Given the fact that the time to solve problems $\mathrm{P} 1$ and $\mathrm{P} 2$, in terms of the number of new facilities, increases exponentially, we have realized (by solving several examples) that for the mentioned special case, the near-optimal solution to the multi-facility problem consists of solving the single-facility problem in different times. That is, for example, if one wants to open two new facilities, one can first solve the singlefacility problem and then, remove the optimal potential location as well as the optimal product; once again, one solves the single-facility problem. Combining the optimal solutions to two sub-problems will be the optimal answer to the main problem. This is absolutely logical, because two different facilities provide two different products and do not cannibalize the market share of each other. Therefore, the first and second best solutions to the single-facility problem will be near optimal solutions to the two-facility problem.

The flowchart of the proposed heuristic is shown in Figure 2.

\subsection{A Hybrid Heuristic-Discrete Firefly Algorithm (HHDFA)}

Firefly algorithm was presented by Yang [71] and it was inspired by social behavior of fireflies. Firefly is a powerful population-based meta-heuristic technique for solving combinatorial optimization problems. Yang [72] indicated that the firefly algorithm was an efficient method for finding the global optima with high success rates.

In the firefly algorithms, attractiveness of a firefly is proportional to its brightness. Thus, the less bright firefly will move toward the brighter one between any pair of flashing fireflies. For a maximization problem, brightness of a firefly can be determined by the value of the objective function. Attractiveness and brightness both increase as distance decreases. If there is no brighter one than a particular firefly, it will move randomly [73]. Sayadi et al. [74] suggested a discrete firefly algorithm for flow shop scheduling problem. Sadjadi et al. [67] presented a hybrid continuous and discrete firefly algorithm for the competitive locationdesign model.

In this paper, discrete firefly is used for obtaining location variable. Once the location is obtained in each iteration, the optimal product type is selected using a heuristic method. Here, the developed HDDFA is described.

\subsubsection{Representation scheme}

A proper encoding scheme, which is indicative of the characteristics of a solution, has considerable influence on the performance of a meta-heuristic method. The encoding scheme of a solution for the location variable is illustrated in Table 3 . This scheme denotes the location of the new facilities for a special firefly, which is indicated by an $o \times r$ matrix.

The location of firefly $i$ in the generation $t$ can be denoted by $X_{i}^{t}=\left(X_{i 11}^{t}, X_{i 12}^{t}, \ldots, X_{i o r}^{t}\right)$. The value of 1 shows the location of a new facility. For example, $X_{i k l}^{t}$ is a binary number and $X_{i k l}^{t}=1$ indicates that the 


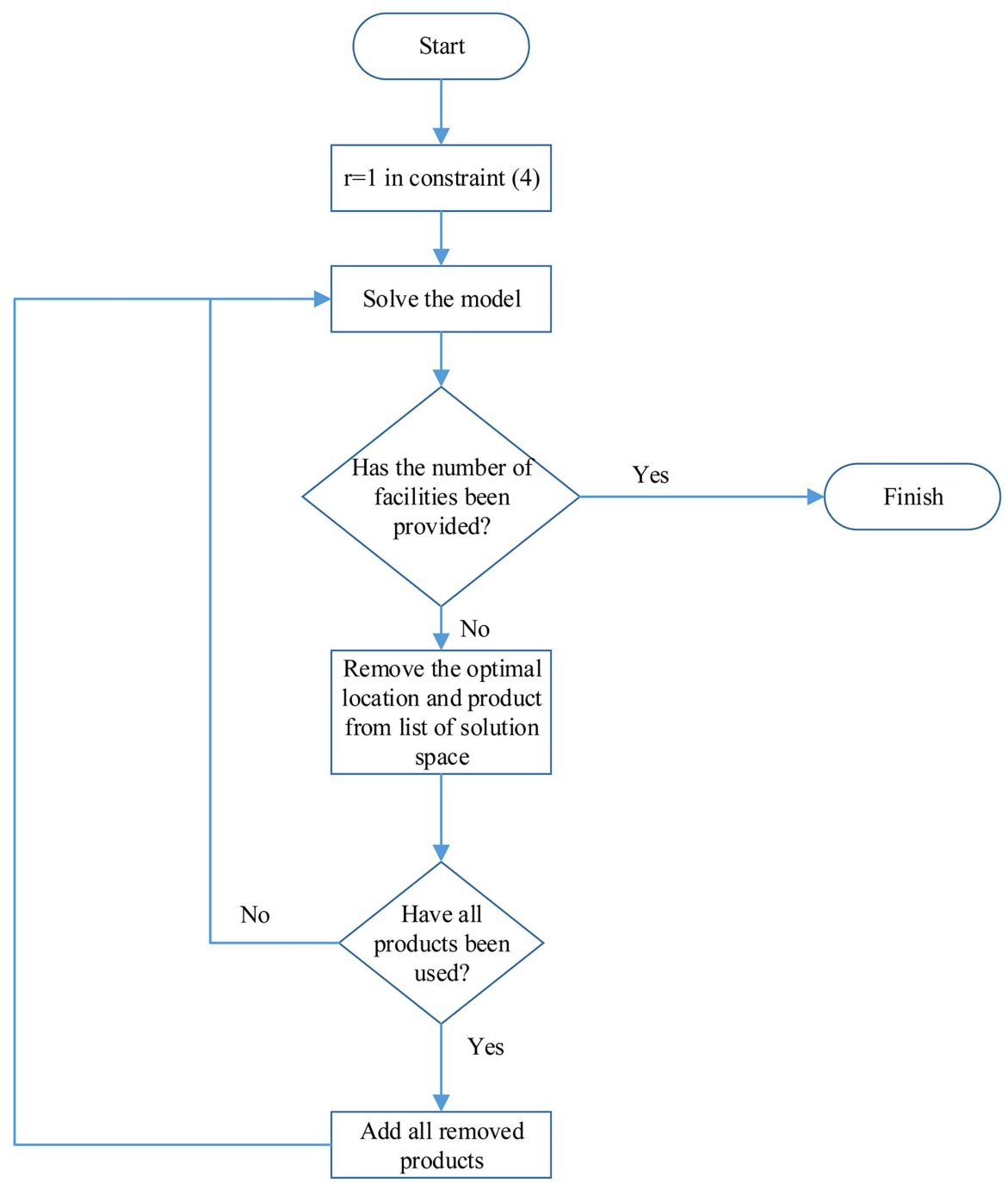

Figure 2. Flowchart of the proposed heuristic.

Table 3. Representation scheme of the solution for firefly $i$ in generation $t$.

\begin{tabular}{ccccc}
\hline \multicolumn{5}{c}{ New facility $(l)$} \\
\hline & $X_{i 11}^{t}$ & $X_{i 12}^{t}$ & $\ldots$ & $X_{i 1 r}^{t}$ \\
& & & & \\
Potential & $X_{i 21}^{t}$ & $X_{i 22}^{t}$ & $\ldots$ & $X_{i 2 r}^{t}$ \\
point (k) & & & & \\
& $\vdots$ & $\vdots$ & $\ldots$ & $\vdots$ \\
& & & & \\
& $X_{i o 1}^{t}$ & $X_{i o 2}^{t}$ & $\ldots$ & $X_{i o r}^{t}$ \\
\hline
\end{tabular}

new facility $l$ of firefly $i$ is placed at the $k$ th potential point in the $t$ th generation and the value of 0 implies otherwise.

\subsubsection{Initialization}

In this paper, the location of new facilities is initialized randomly and a random product is selected for each facility.

\subsubsection{The operators in HHDFA}

In the firefly algorithm, the movement of firefly $i$ toward the more attractive (brighter) firefly $j$ is determined through the following equation [71]:

$$
\begin{aligned}
& X_{i}^{t}=X_{i}^{t}+\beta_{0} e^{-\gamma r_{i j}^{2}}\left(X_{j}^{t}-X_{i}^{t}\right)+\lambda\left(\operatorname{rand}-\frac{1}{2}\right) \\
& m \geq 1
\end{aligned}
$$

where $\beta_{0} e^{-\gamma r_{i j}^{2}}$ is the attractiveness function whose value decreases with increase in the distance between two fireflies $\left(r_{i j}\right) . \beta_{0}$ is attractiveness at $r_{i j}=0$ and $\gamma$ is the fixed light absorption coefficient in the environment. Expression $\lambda\left(\right.$ rand $\left.-\frac{1}{2}\right)$ is for the randomization of movement, in which $\lambda$ is the randomization parameter and "rand" is a function that generates random 


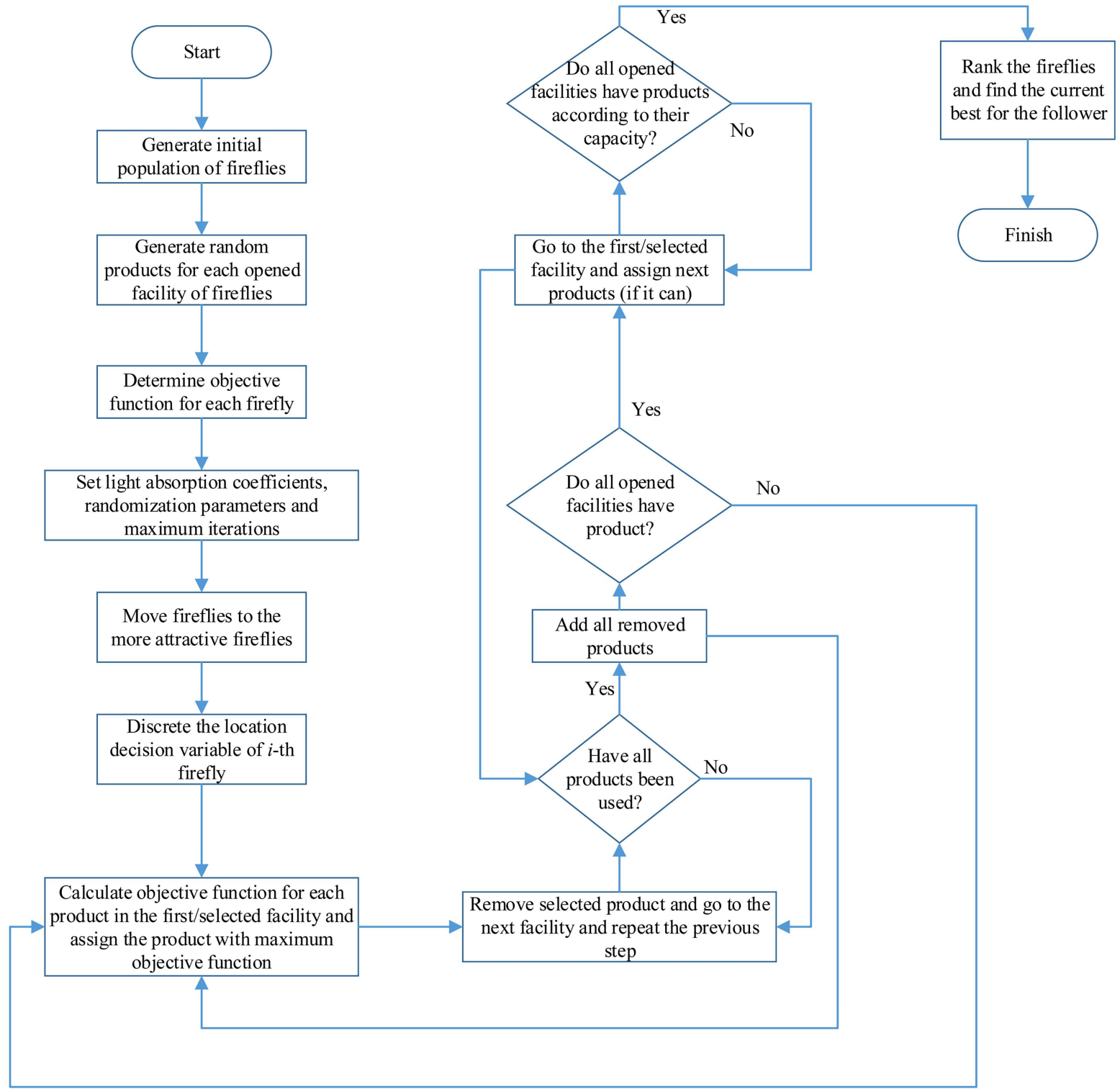

Figure 3. Flowchart of the proposed Hybrid Heuristic-Discrete Firefly Algorithm (HHDFA).

numbers with uniform distribution in the $[0,1]$ interval. By using the Cartesian distance, the distance between fireflies $i$ and $j$ is obtained by the following relation [73]:

$$
r_{i j}=\left\|X_{i}^{t}-X_{j}^{t}\right\|=\sqrt{\sum_{k=1}^{d}\left(X_{i d}^{t}-X_{j d}^{t}\right)^{2}},
$$

where $X_{i d}^{t}$ is the $d$ th component of the $i$ th firefly.

\subsubsection{Discretization}

When firefly $i$ moves toward firefly $j$, the position of firefly $i$ changes from a binary number to a real number. Therefore, this real number must be replaced by a binary value. By using the sigmoid function, the position value is constrained to the interval $[0,1]$ and then, it is transformed into a binary number [74].

\subsubsection{Finding the optimal product}

Once the locations have been selected in each iteration, it is the time to determine products. In this phase, we start with the first facility and the objective function is calculated for different products. The product that leads to the highest value of the objective function is selected and we go to the next facility. At this step, we repeat the same with the remaining products until all products are consumed. Then, we redistribute the products again.

Once the first product of each opened facility is selected, the algorithms will repeat for assigning the next product until all facilities include products based on their capacities.

The flowchart of the proposed HHDFA is shown in Figure 3. 


\section{Numerical examples}

To investigate the performance of the model, first, a small example is solved by MIP solver and the results are analyzed. Then, efficiency of the proposed algorithms is evaluated by solving several examples. Finally, a case study will be presented.

All the computational results in this paper were obtained by a Core i7 $3.5 \mathrm{GHz} \mathrm{CPU}$ with $8 \mathrm{~GB}$ memory. The heuristic method and HHDFA were coded in MATLAB R2018a.

\subsection{An illustrative example}

It is assumed that there are 16 customers, four existing facilities, and four products in a competitive market.
The location and products of the existing facilities of the chain and competitors as well as their qualities are provided in Table 4 .

Table 5 includes the location, demand, and weight for the quality of new facilities for different customers.

The chain wants to open new facilities. Table 6 shows 12 potential locations and their qualities for different products.

Suppose the profit per unit of products 1, 2, 3 , and 4 is $15,11,10$, and 9 , respectively, and the distance between the customers and the new and existing facilities is assumed to be city-block.

If the chain wants to open 1 new facility with 1 product, the optimal location for different products and the optimal product for different locations are quite

Table 4. The location and products of the existing facilities of the chain and the competitors.

\begin{tabular}{ccccc}
\hline & $\begin{array}{c}\text { Existing facilities } \\
\text { of the chain }\end{array}$ & $\begin{array}{c}\text { Existing facilities of } \\
\text { the competitors }\end{array}$ \\
\hline Location coordinates & $(1,3)$ & $(0,3)$ & $(3,1)$ & $(0,0)$ \\
Product type & 1,2 & 3,4 & 2,4 & 1,3 \\
Quality value & 10,6 & 8,8 & 9,4 & 4,9 \\
\hline
\end{tabular}

Table 5. The location and demand of different customers.

\begin{tabular}{|c|c|c|c|c|c|c|c|c|c|c|c|c|c|c|c|c|}
\hline & \multicolumn{16}{|c|}{ Location coordinates } \\
\hline & $(0,0)$ & $(0,1)$ & $(0,2)$ & $(0,3)$ & $(1,0)$ & $(1,1)$ & $(1,2)$ & $(1,3)$ & $(2,0)$ & $(2,1)$ & $(2,2)$ & $(2,3)$ & $(3,0)$ & $(3,1)$ & $(3,2)$ & $(3,3)$ \\
\hline $\begin{array}{l}\text { Weight value } \\
\text { of quality }\end{array}$ & 8 & 8 & 7 & 3 & 3 & 4 & 3 & 5 & 2 & 8 & 10 & 9 & 1 & 10 & 9 & 2 \\
\hline $\begin{array}{l}\text { Demand for } \\
\text { product } 1\end{array}$ & 9 & 24 & 31 & 7 & 59 & 26 & 84 & 74 & 78 & 57 & 44 & 34 & 59 & 63 & 87 & 51 \\
\hline $\begin{array}{l}\text { Demand for } \\
\text { product } 2\end{array}$ & 20 & 31 & 33 & 76 & 81 & 35 & 18 & 61 & 77 & 52 & 90 & 45 & 17 & 4 & 87 & 21 \\
\hline $\begin{array}{l}\text { Demand for } \\
\text { product } 3\end{array}$ & 10 & 87 & 68 & 79 & 53 & 39 & 30 & 93 & 87 & 41 & 28 & 64 & 41 & 20 & 27 & 65 \\
\hline $\begin{array}{l}\text { Demand for } \\
\text { Product } 4\end{array}$ & 36 & 96 & 23 & 34 & 40 & 89 & 29 & 23 & 64 & 39 & 99 & 45 & 41 & 14 & 96 & 87 \\
\hline
\end{tabular}

Table 6. Potential locations and their qualities for different products.

\begin{tabular}{lccccccccccccc}
\hline & \multicolumn{10}{c}{ Location coordinates } \\
\cline { 2 - 13 } & $\mathbf{( 0 , 1 )}$ & $\mathbf{( 0 , 2 )}$ & $\mathbf{( 1 , 0 )}$ & $\mathbf{( 1 , 1 )}$ & $\mathbf{( 1 , 2 )}$ & $\mathbf{( 2 , 0 )}$ & $\mathbf{( 2 , 1 )}$ & $\mathbf{( 2 , 2 )}$ & $\mathbf{( 2 , 3 )}$ & $\mathbf{( 3 , 0 )}$ & $\mathbf{( 3 , 2 )}$ & $\mathbf{( 3 , 3 )}$ \\
\hline Quality of product $\mathbf{1}$ & 8 & 7 & 6 & 10 & 8 & 9 & 8 & 9 & 9 & 7 & 9 & 8 \\
Quality of product & $\mathbf{2}$ & 10 & 7 & 7 & 8 & 7 & 9 & 6 & 10 & 9 & 9 & 6 & 9 \\
Quality of product $\mathbf{3}$ & 6 & 6 & 10 & 7 & 8 & 6 & 10 & 10 & 8 & 7 & 6 & 8 \\
Quality of product & $\mathbf{4}$ & 7 & 9 & 6 & 10 & 8 & 6 & 9 & 8 & 6 & 8 & 9 & 9 \\
\hline
\end{tabular}


Table 7. Optimal locations for different products.

\begin{tabular}{ccc}
\hline Product type & $\begin{array}{c}\text { Optimal location } \\
\text { coordinates }\end{array}$ & $\begin{array}{c}\text { Objective } \\
\text { function (\$) }\end{array}$ \\
\hline 1 & $(2,0)$ & 23,697 \\
2 & $(2,2)$ & 23,692 \\
3 & $(1,0)$ & 23,617 \\
4 & $(2,1)$ & 23,742 \\
\hline
\end{tabular}

Table 8. Optimal products for different potential locations.

\begin{tabular}{ccc}
\hline $\begin{array}{c}\text { Potential } \\
\text { location } \\
\text { coordinates }\end{array}$ & $\begin{array}{c}\text { Optimal } \\
\text { location } \\
\text { coordinates }\end{array}$ & $\begin{array}{c}\text { Objective } \\
\text { function } \\
(\$)\end{array}$ \\
\hline$(0,1)$ & 3 & 23,034 \\
$(0,2)$ & 4 & 22,767 \\
$(1,0)$ & 3 & 23,617 \\
$(1,1)$ & 1 & 23,555 \\
$(1,2)$ & 4 & 23,207 \\
$(2,0)$ & 1 & 23,697 \\
$(2,1)$ & 4 & 23,742 \\
$(2,2)$ & 2 & 23,692 \\
$(2,3)$ & 4 & 22,905 \\
$(3,0)$ & 1 & 23,261 \\
$(3,2)$ & 4 & 23,719 \\
$(3,3)$ & 4 & 23,186 \\
\hline
\end{tabular}

different, which indicates the impact of both variables on each other. In practice, this has been ignored in many mathematical models.

Tables 7 and 8 show the optimal locations and products for different scenarios; they show that the optimal solution is location $(2,1)$ in which product 4 should be offered. If the product is given and fixed, the optimal location will be different and location $(2,1)$ will no longer be considered as the optimal location for products 1,2 , and 3 .

Also, note that if the owner of the chain has the ability to open the facility by offering 2 products, then location $(2,1)$ is not optimal and location (2.2) is the best solution for delivering products 2 and 4 . Table 9 shows the optimal location of the problem when the chain wants to open a facility with 2 products.

Table 9 shows that the optimal location varies with the type of products. Optimal solutions in Tables 4-6 indicate that not only the location and product variables affect each other, but also the number of new facilities as well as the number of products offered by each facility highly affects the optimal solutions. Table 10 summarizes the optimal solutions to the problem under different scenarios.

By comparing the answers, in addition to the
Table 9. Optimal location when the chain wants to open a facility with two products.

\begin{tabular}{ccc}
\hline Product type & $\begin{array}{c}\text { Optimal } \\
\text { location } \\
\text { coordinates }\end{array}$ & $\begin{array}{c}\text { Objective } \\
\text { function } \\
\mathbf{( \$ )}\end{array}$ \\
\hline 1,2 & $(2,0)$ & 25,643 \\
1,3 & $(1,0)$ & 25,593 \\
1,4 & $(2,1)$ & 25,690 \\
2,3 & $(2,1)$ & 25,509 \\
2,4 & $(2,2)$ & 25,840 \\
3,4 & $(2,1)$ & 25,775 \\
\hline
\end{tabular}

results obtained for the impact of variables on each other, two points are notable.

1. Obviously, with increase in the number of facilities or the number of products, profit of the chain will increase. In the mentioned example, it is approximately $10 \%$ for each facility and $9 \%$ for each product. By solving several examples, we understand that increasing the number of branches influences profitability more than the increase in the number of products. The logical reason is that the new facility is located in a new region of customers and can better capture the market;

2. By comparing Tables 10 and 7 , we find that if the chain wants to open multiple facilities, the optimal locations appear in the order shown in Table 7 . By observing this case in other examples, it is concluded that, given the longer time to solve this problem for more new facilities, we can solve the single-facility problem several times according to the number of new facilities. Thus, the CPU time will be considerably reduced. This method was described in Section 3.2.

For investigating the importance of the "locationproduct" model in comparison with the models that do not consider the optimal product, we assume that the owner of the chain chooses one product based on their experience and opens a new facility in one of the potential sites. Table 11 shows the difference in profit (in percent) between the optimal location and other solutions for different products.

Table 11 shows the necessity of using location models, where, in the absence of the model, an average of $2.5 \%$ less profit earning is achieved by the chain. We do the same with the products to see the impact of the optimal product for each potential location in Table 12 .

Table 12 shows the necessity of using the product model, where, in the absence of the model, an average of $1.15 \%$ less profit earning is achieved by the chain. Although the average value is lower than the respective one for the location variable, it is a significant value in many cases. Therefore, in multi-product industries in 
Table 10. Optimal solution under different scenarios.

\begin{tabular}{|c|c|c|c|c|c|c|}
\hline Scenario & Description & $\begin{array}{c}\text { Optimal } \\
\text { location } \\
\text { coordinates }\end{array}$ & $\begin{array}{l}\text { Optimal product } \\
\text { type }\end{array}$ & $\begin{array}{l}\text { Profit } \\
\quad(\$)\end{array}$ & $\begin{array}{c}\text { Increase } \\
\text { in profit }(\$)\end{array}$ & $\begin{array}{l}\text { Increase } \\
\text { rate }(\%)\end{array}$ \\
\hline 0 & Existing condition & - & - & 21,501 & - & - \\
\hline 1 & $\begin{array}{c}\text { Open one new facility with } \\
\text { one product }\end{array}$ & $(2,1)$ & 4 & 23,742 & 2,241 & $10 \%$ \\
\hline 2 & $\begin{array}{l}\text { Open two new facilities with } \\
\text { one product in each one }\end{array}$ & $\begin{array}{l}(2,0) \\
\text { and } \\
(2,1)\end{array}$ & $\begin{array}{c}1 \\
\text { and } \\
4\end{array}$ & 25,937 & 4,436 & $21 \%$ \\
\hline 3 & $\begin{array}{l}\text { Open one new facility with } \\
\text { two products }\end{array}$ & $(2,2)$ & 2 and 4 & 25,840 & 4,339 & $20 \%$ \\
\hline 4 & $\begin{array}{l}\text { Open three new facilities with } \\
\text { one product in each one }\end{array}$ & $\begin{array}{c}(2,0), \\
(2,1), \\
\text { and } \\
(2,2)\end{array}$ & 1,4 , and 2 & 28,128 & 6,627 & $31 \%$ \\
\hline 5 & $\begin{array}{l}\text { Open one new facility with } \\
\text { three products in each one }\end{array}$ & $(2,1)$ & 2,3 , and 4 & 27,750 & 6,249 & $29 \%$ \\
\hline 6 & $\begin{array}{l}\text { Open four new facilities with one } \\
\text { product in each one }\end{array}$ & $\begin{array}{l}(1,0), \\
(2,0), \\
(2,1), \\
\text { and } \\
(2,2)\end{array}$ & $\begin{array}{c}3,1,4 \text {, and } \\
2\end{array}$ & 30,244 & 8743 & $41 \%$ \\
\hline 7 & $\begin{array}{l}\text { Open one new facility with four } \\
\text { products in each one }\end{array}$ & $(2,1)$ & $1,2,3$, and & 29,699 & 8,198 & $38 \%$ \\
\hline
\end{tabular}

Table 11. Difference in profit (\%) between optimal location and other solutions for different products.

\begin{tabular}{ccc}
\hline Product type & $\begin{array}{c}\text { Worst } \\
\text { solution } \\
(\%)\end{array}$ & $\begin{array}{c}\text { Average } \\
\text { solution } \\
\mathbf{( \% )}\end{array}$ \\
\hline Product 1 & $5.13 \%$ & $2.67 \%$ \\
Product 2 & $5.04 \%$ & $2.47 \%$ \\
Product 3 & $4.91 \%$ & $2.61 \%$ \\
Product 4 & $4.22 \%$ & $2.24 \%$ \\
\hline
\end{tabular}

which the owner of the facilities is able to offer different types of products, in addition to the optimal location, determining the best product should be considered.

\subsection{Solution methods efficiency}

We provide some experimental results to investigate the efficiency of MIP solver, heuristic method, and HHDFA. For this purpose, we have generated various problems in which the number of customers ( $n=25,50,100)$, the number of existing facilities
Table 12. Difference in profit (\%) between optimal product and other solutions for different potential locations.

\begin{tabular}{ccc}
\hline $\begin{array}{c}\text { Potential } \\
\text { location } \\
\text { coordinates }\end{array}$ & $\begin{array}{c}\text { Worst } \\
\text { solution } \\
\mathbf{( \% )}\end{array}$ & $\begin{array}{c}\text { Average } \\
\text { solution } \\
\mathbf{( \% )}\end{array}$ \\
\hline$(0,1)$ & $1.28 \%$ & $0.63 \%$ \\
$(0,2)$ & $1.26 \%$ & $0.87 \%$ \\
$(1,0)$ & $3.06 \%$ & $1.54 \%$ \\
$(1,1)$ & $1.41 \%$ & $0.78 \%$ \\
$(1,2)$ & $1.51 \%$ & $1.00 \%$ \\
$(2,0)$ & $2.40 \%$ & $1.25 \%$ \\
$(2,1)$ & $1.23 \%$ & $0.80 \%$ \\
$(2,2)$ & $2.59 \%$ & $1.29 \%$ \\
$(2,3)$ & $1.34 \%$ & $0.66 \%$ \\
$(3,0)$ & $1.06 \%$ & $0.45 \%$ \\
$(3,2)$ & $4.77 \%$ & $2.59 \%$ \\
$(3,3)$ & $3.14 \%$ & $1.92 \%$ \\
\hline
\end{tabular}

$(m=5,10)$, the number of potential locations ( $o=$ $25,50,100)$, the number of products $(p=5,10)$, and the number of new facilities $(r=2,4,10)$ are changed. In all cases, the number of the facilities of the 
chain is $f=2$ for $m=5$ and $f=4$ for $m=10$. The maximum number of new facilities that offer a given product equals the number of new facilities and the maximum number of products to be delivered at potential locations is 1 (the assumption for using heuristic method).

For each setting, five examples have been created in which the parameters of the problems are randomly chosen from the following intervals:

$$
\begin{aligned}
& b_{j t} \sim U(1,100), \quad d_{i j} \sim U(1,10), \quad d_{k j} \sim U(1,10), \\
& \gamma_{j} \sim U(0.01,1), \quad \alpha_{i t} \sim U(1,10), \quad q_{k t} \sim U(5,10), \\
& p r_{t} \sim U(10,20), \quad \varepsilon=0.05 .
\end{aligned}
$$

\subsubsection{Values of the parameters of HHDFA}

$\gamma$ should be related to the scales of design variables of a problem. For example, one possible choice is to set $\gamma=1 / \sqrt{L}$ where $L$ is the average scale of the problem. After comparing different values for $\gamma$, the value of 0.6 is selected. For most cases, we set $\beta_{0}=1$ and $\lambda \in[0,1]$. Comparing different values for $\lambda$, the value of 0.2 is suitable.

The optimal solution can be found after about 500 evaluations for most cases. Therefore, 25 fireflies and 20 generations have been selected in the computational experiment.

\subsubsection{The results}

To evaluate the solution quality of the proposed algorithm, HHDFA with 10 runs and heuristic method for each problem have been compared with the optimal solver for the small- and medium-size instances.

First, we show the results for a typical setting in detail. The difference between the optimal value obtained by the optimal solver and the solution obtained by the heuristic and HHDFA in addition to the CPU times spent by the Mixed Integer Nonlinear Programming (MINLP) solver, MIP solver, heuristic method, and HHDFA for the five generated examples of the cases $n=25, m=5, o=25, p=5, r=2$, is presented in Table 13. The last two lines show the total average and total standard deviation.

Effectiveness (the capability of the method for obtaining the optimal solution) of the proposed algorithms in small instances is depicted in Table 13.

From now on, only the total average values are shown for investigating the results. In terms of different numbers of potential locations, the summarized information (like the last two lines of Table 13) has been classified and presented in Table 14 . The values in the table are related to the average and the values in brackets are standard deviations. In the last line, the average for the setting, regardless of the number of potential locations, is given.

Note that when the number of potential locations

\begin{tabular}{|c|c|c|c|c|c|c|}
\hline \multirow[t]{2}{*}{ Problem } & \multicolumn{2}{|c|}{ Difference in obj (\%) } & \multicolumn{4}{|c|}{ CPU time (seconds) } \\
\hline & Heuristic & HHDFA & MINLP solver & MIP solver & Heuristic & HHDFA \\
\hline 1 & 0.00 & 0.02 & 71.46 & 62.58 & 12.24 & 4.28 \\
\hline 2 & 0.00 & 0.03 & 67.00 & 66.58 & 13.89 & 4.39 \\
\hline 3 & 0.00 & 0.02 & 58.35 & 57.13 & 10.34 & 5.01 \\
\hline 4 & 0.00 & 0.02 & 73.81 & 69.05 & 13.82 & 3.59 \\
\hline 5 & 0.00 & 0.01 & 55.10 & 54.19 & 10.07 & 4.22 \\
\hline Average & 0.00 & 0.02 & 65.14 & 61.91 & 12.07 & 4.30 \\
\hline Standard deviation & 0.00 & 0.01 & 8.15 & 6.24 & 1.83 & 0.45 \\
\hline
\end{tabular}

Table 13. Differences between objectives and CPU times for the 5 examples with 25 customers, 5 existing facilities, 25 potential locations, 5 products and, 2 new facilities.

\begin{tabular}{|c|c|c|c|c|c|c|}
\hline \multirow{2}{*}{$\begin{array}{l}\text { Number of } \\
\text { potential } \\
\text { locations }\end{array}$} & \multicolumn{2}{|c|}{ Difference in obj (\%) } & \multicolumn{4}{|c|}{ CPU time (seconds) } \\
\hline & Heuristic & HHDFA & MINLP solver & MIP solver & Heuristic & HHDFA \\
\hline 25 & $0.00(0.00)$ & $0.02(0.01)$ & $65.14(8.15)$ & $61.91(6.24)$ & $12.07(1.83)$ & $4.30(0.45)$ \\
\hline 50 & $0.00(0.00)$ & $0.34(0.18)$ & $105.87(17.92)$ & $84.14(8.52)$ & $19.81(2.05)$ & $7.02(2.29)$ \\
\hline 100 & $0.01(0.01)$ & $0.83(0.26)$ & $318.69(51.38)$ & $195.43(15.21)$ & $29.41(3.44)$ & $11.52(4.26)$ \\
\hline All & $0.00(0.01)$ & $0.39(0.16)$ & $163.23(22.67)$ & $113.82(29.97)$ & $20.43(7.32)$ & $7.61(2.41)$ \\
\hline
\end{tabular}

Table 14. The average and standard deviation values of the differences between objectives and CPU times for the examples with 25 demand points; 5 existing facilities; 5 products; 2 new facilities; and 25, 50, and 100 potential locations. 
Table 15. The average and standard deviation values of the differences between objectives and CPU times for the examples with 25 demand points; 5 existing facilities; 5 products; 100 potential locations; and 2, 4, and 10 new facilities.

\begin{tabular}{|c|c|c|c|c|c|c|}
\hline \multirow{2}{*}{$\begin{array}{l}\text { Number } \\
\text { of new } \\
\text { facilities }\end{array}$} & \multicolumn{2}{|c|}{ Difference in obj (\%) } & \multicolumn{4}{|c|}{ CPU time (seconds) } \\
\hline & Heuristic & HHDFA & MINLP solver & MIP solver & Heuristic & HHDFA \\
\hline 2 & $0.01(0.01)$ & $0.83(0.26)$ & $318.69(51.38)$ & $195.43(15.21)$ & $29.41(3.44)$ & $11.52(4.26)$ \\
\hline 4 & $0.51(0.03)$ & $1.75(0.40)$ & $849.96(110.57)$ & 299. $81(22.12)$ & $37.74(4.18)$ & $14.03(5.29)$ \\
\hline 10 & $1.27(0.16)$ & $3.93(0.98)$ & $1830.87(203.24)$ & $508.69(36.19)$ & $93.35(10.25)$ & $26.59(8.11)$ \\
\hline All & $0.59(0.06)$ & $2.17(50.14)$ & $999.84(121.73)$ & $334.64(24.51)$ & $53.50(5.95)$ & $17.38(6.02)$ \\
\hline
\end{tabular}

Table 16. CPU time for the problems with 100 potential locations and 10 new facilities.

\begin{tabular}{|c|c|c|c|c|c|}
\hline \multirow{2}{*}{$\begin{array}{l}\text { Number of } \\
\text { customers }\end{array}$} & \multirow{2}{*}{$\begin{array}{c}\text { Number of } \\
\text { existing } \\
\text { facilities }\end{array}$} & \multirow{2}{*}{$\begin{array}{l}\text { Number of } \\
\text { products }\end{array}$} & \multicolumn{3}{|c|}{ CPU time (seconds) } \\
\hline & & & MIP solver & Heuristic & HHDFA \\
\hline \multirow{4}{*}{25} & \multirow{2}{*}{5} & 5 & $509(36)$ & $93(10)$ & $27(8)$ \\
\hline & & 10 & $601(41)$ & $129(16)$ & $34(10)$ \\
\hline & \multirow{2}{*}{10} & 5 & $528(37)$ & $110(12)$ & $29(7)$ \\
\hline & & 10 & $645(44)$ & $141(19)$ & $35(7)$ \\
\hline \multirow{4}{*}{50} & \multirow{2}{*}{5} & 5 & $629(41)$ & $139(17)$ & $35(8)$ \\
\hline & & 10 & $741(52)$ & $206(25)$ & $49(11)$ \\
\hline & \multirow{2}{*}{10} & 5 & $677(43)$ & $154(22)$ & $41(10)$ \\
\hline & & 10 & $845(59)$ & $211(29)$ & $50(13)$ \\
\hline \multirow{4}{*}{100} & \multirow[t]{2}{*}{5} & 5 & $799(54)$ & $194(20)$ & $46(8)$ \\
\hline & & 10 & $883(62)$ & $309(32)$ & $65(19)$ \\
\hline & \multirow{2}{*}{10} & 5 & $841(57)$ & $200(22)$ & $49(12)$ \\
\hline & & 10 & $939(68)$ & $326(38)$ & $71(21)$ \\
\hline
\end{tabular}

increases, the increase in solution times of the optimal solvers, especially MINLP solver, is more than those of the proposed methods. In fact, HHDFA is much faster than the other two solvers and the heuristic for largesize problems. The quality of the heuristic is slightly better than that of HHDFA, but the quality of the results of HHDFA is still good enough. This issue is more clearly seen in Table 15, in which the number of new facilities is increased.

According to Table 15, increasing the number of new facilities leads to significant increase in the solution times of the MINLP and MIP Solvers, while the heuristic method and HHDFA are less sensitive.

Since the difference in objective functions of the heuristic method, even in large-size problems, is below $1 \%$ and it requires a reasonable solving time, this method is very practical in the special case mentioned in Section 3.2. Regarding the HHDFA method, it can be said that although its quality is to some extent less than the heuristic method, the percentage of difference in its objective functions is still acceptable. Since it can be used in general cases and has an acceptable solving time, it is a good method for solving general examples, while for the special case, the heuristic method is suggested.

Table 16 depicts the results for large examples with up to 100 customers obtained by MIP solver, heuristic method, and HHDFA, which could not be worked out using MINLP solver.

According to Table 16, the increase in the number of customers and facilities will increase the CPU time for solving the model, but not as large as the number of new facilities and the number of products do, because they are decision variables and increase the solution space, making it more difficult to find the optimal solution.

In Table 17, some problems are solved by considering the value of 2 for Constraint (6). Since the 
Table 17. CPU time for the problems with 100 potential locations, 100 customers, and 10 new facilities.

\begin{tabular}{cccc}
\hline \multirow{2}{*}{$\begin{array}{c}\text { Number of existing } \\
\text { facilities }\end{array}$} & $\begin{array}{c}\text { Number of } \\
\text { products }\end{array}$ & \multicolumn{2}{c}{ CPU time (seconds) } \\
\cline { 3 - 4 } & 5 & MIP solver & HHDFA \\
\hline 5 & 10 & $4323(201)$ & $71(17)$ \\
& & & \\
\multirow{2}{*}{10} & 5 & $4164(198)$ & $85(19)$ \\
& 10 & $5594(305)$ & $105(27)$ \\
\hline
\end{tabular}

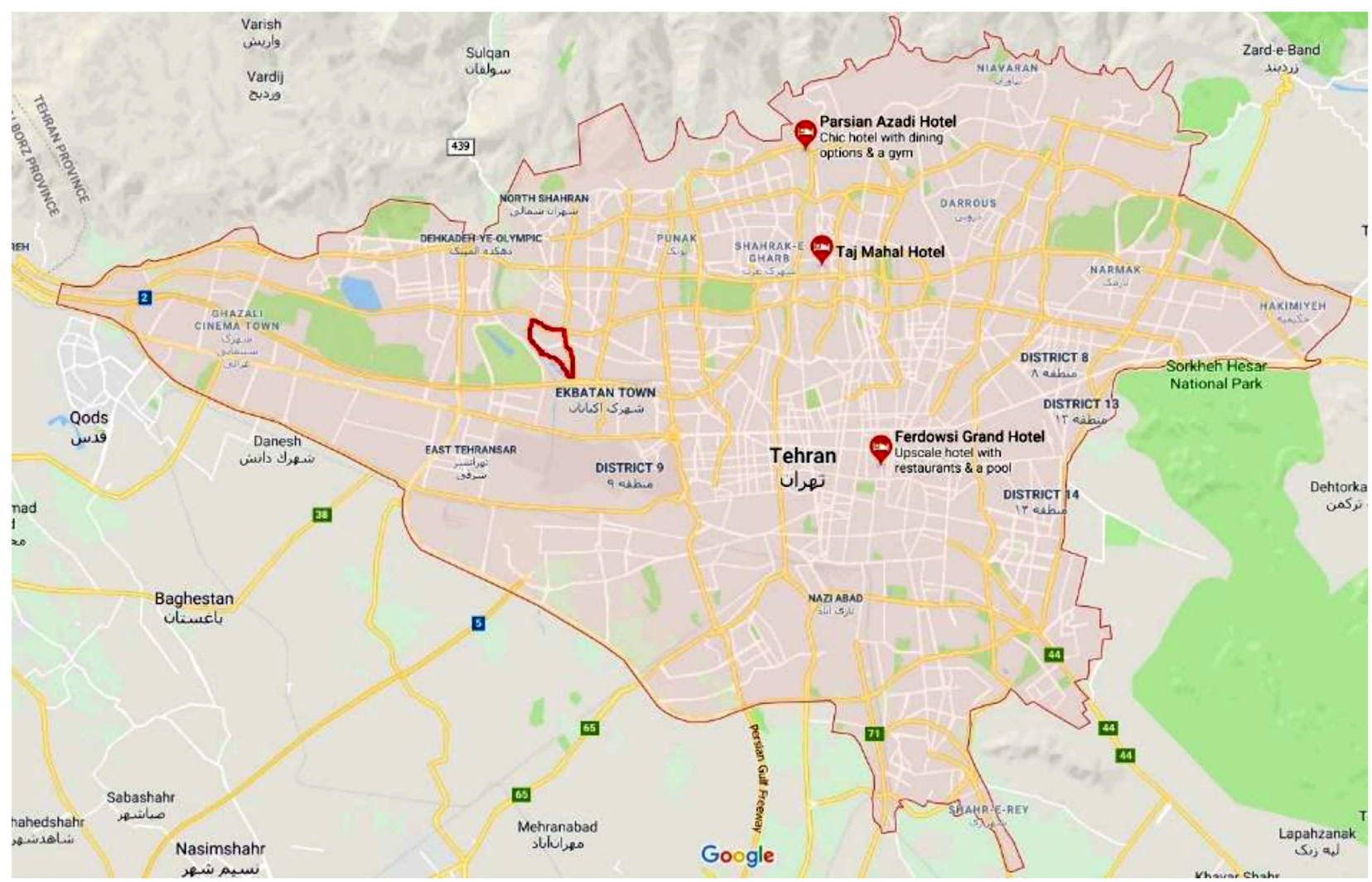

Figure 4. Sector Eram, district 5, Tehran map.

heuristic method is no longer able to solve the problem, the comparison is between CPU times of only the MIP solver and HHDFA.

Opening up to 10 new facilities with up to 10 different product groups can be a real problem, because many chains may not be able to open more than this number of new facilities. Tables 16 and 17 show effectiveness of all the three methods, especially the heuristic (for the special case) and HHDFA (for general cases). In less than 10 minutes (for heuristic) and two minutes (for HHDFA), a problem with 100 customers, 100 potential locations, 10 existing facilities, 10 products, and 10 new facilities can be solved with reasonable solutions.

\subsection{A real-world application}

In this section, a real-world case study of the proposed model is presented. The model has been used for the new facility location for a bakery in sector Eram, district 5, Tehran, as depicted with red line in Figure 4 .

Various types of bread are produced in Iran and each of them requires different equipment and furnace for production and each bakery often produces one specific type of bread. Three types of bread that are more popular than others are Barbari, Sangak, and Lavash.

We divided the sector into 10 areas and considered each one as a customer. Figure 5 shows how the sector is divided.

As the goods are necessary and the demand has no specific relationship with the level of income, the population of each area can be considered as $b_{j t}$. The latitude and longitude of different areas of this sector, calculated by LatLon system, as well as the normalized population for each area are depicted in Table 18. 


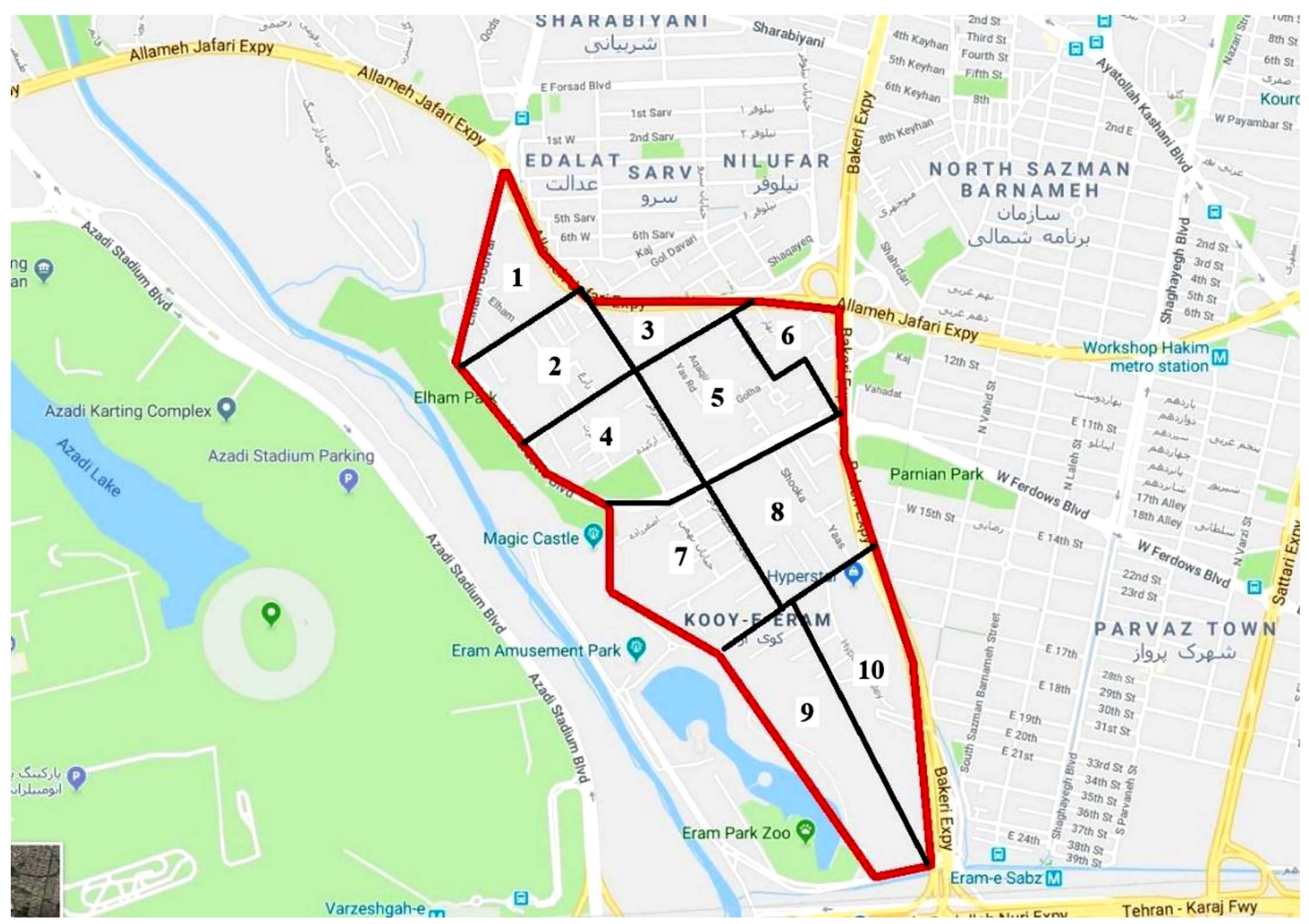

Figure 5. Different areas of Eram sector.

Table 18. Location and population of different areas.

\begin{tabular}{ccccc}
\hline \# Area & Latitude (degree) & Longitude (degree) & $\begin{array}{c}\text { Weight of } \\
\text { quality }\end{array}$ & $\begin{array}{c}\text { Normalized } \\
\text { population }\end{array}$ \\
\hline 1 & 51.28374 & 35.73405 & 1 & 20 \\
2 & 51.28519 & 35.73149 & 1 & 85 \\
3 & 51.28873 & 35.73287 & 1 & 25 \\
4 & 51.28699 & 35.72953 & 1 & 30 \\
5 & 51.29054 & 35.73146 & 1 & 70 \\
6 & 51.29346 & 35.73219 & 1 & 50 \\
7 & 51.29012 & 35.72617 & 1 & 70 \\
8 & 51.29322 & 35.72750 & 1 & 60 \\
9 & 51.29345 & 35.72415 & 1 & 40 \\
10 & 51.29505 & 35.72456 & 1 & 30 \\
\hline
\end{tabular}

The consumption rates of Barbari, Sangak, and Lavash are 1.2, 1, and 3, respectively (these values are used to compute $b_{j t}$ ). There are four existing facilities in this sector for offering the mentioned three types of bread. Using LatLon system, the latitude and longitude as well as the products of the existing facilities have been depicted in Table 19.

The levels of the quality of the existing facilities have been determined by the customers through a questionnaire designed by SERVQUAL $[75,76]$.

The level of modern looking building and equipment, the level of staff training for treating customers, the level of materials associated with service (promotional brushers and service tracking documents), providing gifts for customers as a promotion, and allocating special personnel with high public relation to 
Table 19. Location and products of existing facilities.

\begin{tabular}{cccc}
\hline \# Facility & Latitude (degree) & Longitude (degree) & Product(s) \\
\hline 1 & 51.28362 & 35.73308 & Lavash \\
2 & 51.28974 & 35.72937 & Lavash-Barbari-Sangak \\
3 & 51.29225 & 35.72606 & Lavash-Barbari-Sangak \\
4 & 51.28937 & 35.73171 & Sangak \\
\hline
\end{tabular}

Table 20. The quality of existing facilities for different products.

\begin{tabular}{cccc}
\hline \# Facility & $\begin{array}{c}\text { Barbari quality } \\
\text { value }\end{array}$ & $\begin{array}{c}\text { Sangak quality } \\
\text { value }\end{array}$ & $\begin{array}{c}\text { Lavash quality } \\
\text { value }\end{array}$ \\
\hline 1 & - & - & 4.2 \\
2 & 5.1 & 6.3 & 5.2 \\
3 & 8.1 & 8.2 & 7.9 \\
4 & - & 7.3 & - \\
\hline
\end{tabular}

Table 21. The potential locations and max number of products.

\begin{tabular}{cccc}
\hline $\begin{array}{c}\text { \# Potential } \\
\text { location }\end{array}$ & $\begin{array}{c}\text { Latitude } \\
\text { (degree) }\end{array}$ & $\begin{array}{c}\text { Longitude } \\
\text { (degree) }\end{array}$ & $\begin{array}{c}\text { Max. number } \\
\text { of products }\end{array}$ \\
\hline 1 & 51.28625 & 35.73080 & 2 \\
2 & 51.28692 & 35.73251 & 2 \\
3 & 51.29063 & 35.73297 & 1 \\
4 & 51.29224 & 35.73176 & 1 \\
5 & 51.28868 & 35.73027 & 2 \\
6 & 51.29062 & 35.72779 & 1 \\
7 & 51.29034 & 35.72581 & 1 \\
8 & 51.29175 & 35.72476 & 1 \\
10 & 51.29385 & 35.72423 & 1 \\
\hline
\end{tabular}

respond to the probable questions of the customers and to keep in contact with them (e.g., informing them of the new products) are examples of quality dimensions of the facilities, which are evaluated by the customers.

For each existing facility, 400 customers were chosen as a sample and the Cronbach's alpha for the designed questionnaire was 0.83. The paired comparison matrix was used for extracting the weights of different criteria as well. Customer evaluations were aggregated for obtaining the total design (quality) score in the scale of 1 to 10 , as depicted in Table 20 .
There are nine potential locations as the candidates and their latitude and longitude as well as maximum number of products to be offered are depicted in Table 21.

The profits per unit of products Barbari, Sangak, and Lavash are 500, 600, and 200, respectively. The optimal solutions for different scenarios of this real application are depicted in Table 22 .

\section{Conclusion}

In this paper, a Competitive Facility Location (CFL) model has been formulated under a condition that a chain can offer different types of products. For this model, we needed to determine the optimal location and the optimal products.

We formulated this problem in a static competition in which the competitors of a given company were already on the market and the company was aware of the characteristics of the facilities. The patronizing behavior of the customers was modeled according to Huff rule. The solution space of the model was discrete and the optimal locations should be selected from the potential locations set. Obviously, the product space was also discrete and, as a result, the problem was an integer nonlinear programming problem. We reformulated the problem into a mixed integer linear formulation. Mixed Integer Programming (MIP) solvers could be easily applied to solving the model

Table 22. The optimal solution in each scenario.

\begin{tabular}{cccc}
\hline \# Scenario & Description & $\begin{array}{c}\text { \# Optimal } \\
\text { location(s) }\end{array}$ & $\begin{array}{c}\text { Optimal product } \\
(\mathbf{s})\end{array}$ \\
\hline 1 & Open one new facility with one product & 4 & $\begin{array}{c}\text { Barbari } \\
2\end{array}$ \\
3 & Open two new facilities with one product in each one & 4 and 3 & $\begin{array}{c}\text { Barbari and Lavash } \\
\text { Barbari and Lavash }\end{array}$ \\
4 & Open one new facility with two products & 5 & Barbari, Lavash, and Sangak \\
\hline
\end{tabular}


at least for small- and medium-size problems with a reasonable CPU time.

We developed a heuristic and a hybrid heuristicfirefly algorithm for solving the large-scale problems. The results showed that the difference between the objective values of the solutions and the optimal solvers was small even for large-size problems. The obtained results indicated that in the multi-product industries, the chain should consider the product variable, in addition to the location. As it was seen in this paper, the optimal solution in the chain was different for various products. Therefore, neglecting product selection might impact the optimal solution and cause a major damage.

As a future research, it is interesting to study this problem in a leader-follower situation. Furthermore, considering other patronizing behavior assumptions is suggested. Also, the taste of each region (about the type of product) can be considered as a factor in the objective function for further research.

\section{References}

1. Snyder, L.V. "Facility location under uncertainty: a review", IIE Transactions, 38(7), pp. 547-564 (2006).

2. Zarandi, M.F., Davari, S., and Sisakht, S.H. "The large-scale maximal covering location problem", Scientia Iranica, 18(6), pp. 1564-1570 (2011).

3. Karimi, H. and Bashiri, M. "Hub covering location problems with different coverage types", Scientia Iranica, 18(6), pp. 1571-1578 (2011).

4. Melo, M.T., Nickel, S., and Saldanha-Da-Gama, F. "Facility location and supply chain management-A review", European Journal of Operational Research, 196(2), pp. 401-412 (2009).

5. Owen, S.H. and Daskin, M.S. "Strategic facility location: A review", European Journal of Operational Research, 111(3), pp. 423-447 (1998).

6. Hotelling, H. "Stability in competition", Economic Journal, 39, pp. 41-57 (1929).

7. Hakimi, S.L. "On locating new facilities in a competitive environment", in ISOLDE II Conference, Skodsborg, Denmark (1981).

8. Hakimi, S.L. "On locating new facilities in a competitive environment", European Journal of Operational Research, 12, pp. 29-35 (1983).

9. Hakimi, S.L. "p-median theorems for competitive location", Annals of Operations Research, 6, pp. 77-98 (1986).

10. Hakimi, S.L. "Locations with spatial interactions: Competitive locations and games", in P.B. Mirchandani and R.L. Francis, Eds., Discrete Location Theory, Wiley-Interscience, New York, NY, pp. 439-478 (1990).

11. Drezner, Z. "Competitive location strategies for two facilities", Regional Science and Urban Economics, 12, pp. 485-493 (1982).
12. Huff, D. "Defining and estimating a trading area", Journal of Marketing, 28, pp. 34-38 (1964).

13. Huff, D.L. "A programmed solution for approximating an optimum retail location", Land Economics, 42, pp. 293-303 (1966).

14. Eiselt, H.A., Laporte, G., and Thisse, J.F. "Competitive location models: A framework and bibliography", Transportation Science, 27(1), pp. 44-54 (1993).

15. Plastria, F. "Static competitive facility location: an overview of optimisation approaches", European Journal of Operational Research, 129(3), pp. 461-470 (2001).

16. Drezner, T. "A review of competitive facility location in the plane", Logistics Research, 7(1), pp. 1-12 (2014).

17. Ashtiani, M. "Competitive location: a state-of-art review", International Journal of Industrial Engineering Computations, 7(1), pp. 1-18 (2016).

18. Beresnev, V. and Melnikov, A. "Exact method for the capacitated competitive facility location problem", Computers \& Operations Research, 95, pp. 73-82 (2018).

19. Plastria, F. and Carrizosa, E. "Optimal location and design of a competitive facility", Mathematical Programming, 100(2), pp. 247-265 (2004).

20. Hendrix, E.M. "On competition in a Stackelberg location-design model with deterministic supplier choice", Annals of Operations Research, 246(1-2), pp. 19-30 (2016).

21. Fernández, J., Pelegrín, B., Plastria, F., et al. "Planar location and design of a new facility with inner and outer competition: an interval lexicographical-like solution procedure", Networks and Spatial Economics, 7(1), pp. 19-44 (2007).

22. Wang, X. and Ouyang, Y. "A continuum approximation approach to competitive facility location design under facility disruption risks", Transportation Research Part B: Methodological, 50, pp. 90-103 (2013).

23. Fernández, J., Boglárka, G., Redondo, J.L., et al. "A planar single-facility competitive location and design problem under the multi-deterministic choice rule". Computers \& Operations Research, 78, pp. 305-315 (2017).

24. Aboolian, R., Berman, O., and Krass, D. "Competitive facility location and design problem", European Journal of Operational Research, 182(1), pp. 40-62 (2007).

25. Arrondo, A.G., Redondo, J.L., Fernández, J., et al. "Solving a leader-follower facility problem via parallel evolutionary approaches", The Journal of Supercomputing, 70(2), pp. 600-611 (2014).

26. Fernández, J., Pelegrı, B., Plastria, F., et al. "Solving a Huff-like competitive location and design model for profit maximization in the plane", European Journal of Operational Research, 179(3), pp. 1274-1287 (2007).

27. Küçükaydin, H., Aras, N., and Altınel, I.K. "Competitive facility location problem with attractiveness adjustment of the follower: A bilevel programming 
model and its solution", European Journal of Operational Research, 208(3), pp. 206-220 (2011).

28. Redondo, J.L., Arrondo, A.G., Fernández, J., et al. "A two-level evolutionary algorithm for solving the facility location and design (1| 1)-centroid problem on the plane with variable demand", Journal of Global Optimization, 56(3), pp. 983-1005 (2013).

29. Redondo, J.L., Fernandez, J., Garcia, I., et al. "Parallel algorithms for continuous competitive location problems", Optimisation Methods \& Software, 23(5), pp. 779-791 (2008).

30. Redondo, J.L., Fernández, J., García, I., et al. "Sensitivity analysis of a continuous multifacility competitive location and design problem", Top, 17(2), p. 347 (2009).

31. Redondo, J.L., Fernández, J., García, I., et al. "Heuristics for the facility location and design (1|1)-centroid problem on the plane", Computational Optimization and Applications, 45(1), pp. 111-141 (2010).

32. Saidani, N., Chu, F., and Chen, H. "Competitive facility location and design with reactions of competitors already in the market", European Journal of Operational Research, 219(1), pp. 9-17 (2012).

33. Sáiz, M.E., Hendrix, E.M., and Pelegrín, B. “On Nash equilibria of a competitive location-design problem", European Journal of Operational Research, 210(3), pp. 588-593 (2011).

34. Arrondo, A.G., Fernández, J., Redondo, J.L., et al. "An approach for solving competitive location problems with variable demand using multicore systems", Optimization Letters, 8(2), pp. 555-567 (2014).

35. Arrondo, A.G., Redondo, J.L., Fernández, J., et al. "Parallelization of a non-linear multi-objective optimization algorithm: application to a location problem", Applied Mathematics and Computation, 255, pp. 114-124 (2015).

36. Fernández, J., Tóth, B., Plastria, F., et al. "Reconciling franchisor and franchisee: a planar biobjective competitive location and design model", In Recent Advances in Optimization, pp. 375-398, Springer, Berlin, Heidelberg (2006).

37. Küçükaydın, H., Aras, N., and Altınel, İ.K. "A discrete competitive facility location model with variable attractiveness", Journal of the Operational Research Society, 62(9), pp. 1726-1741 (2011).

38. Küçükaydın, H., Aras, N., and Altınel, İ.K. "A leaderfollower game in competitive facility location", Computers \& Operations Research, 39(2), pp. 437-448 (2012).

39. Lančinskas, A., Ortigosa, P.M., and Žilinskas, J. "Parallel shared-memory multi-objective stochastic search for competitive facility location", In European Conference on Parallel Processing, pp. 71-82, Springer, Cham (2014, August).
40. Redondo, J.L., Fernández, J., Arrondo, A.G., et al. "Fixed or variable demand? Does it matter when locating a facility?", Omega, 40(1), pp. 9-20 (2012).

41. Redondo, J.L., Fernández, J., García, I., et al. "A robust and efficient algorithm for planar competitive location problems", Annals of Operations Research, 167(1), pp. 87-105 (2009).

42. Redondo, J.L., Fernández, J., García, I., et al. "Solving the multiple competitive facilities location and design problem on the plane", Evolutionary Computation, 17(1), pp. 21-53 (2009).

43. Redondo, J.L., Fernández, J., Hervás, J.D.Á., et al. "Approximating the Pareto-front of a planar biobjective competitive facility location and design problem", Computers \& Operations Research, 62, pp. 337349 (2015).

44. Tóth, B., Fernández, J., Pelegrín, B., et al. "Sequential versus simultaneous approach in the location and design of two new facilities using planar Huff-like models", Computers \& Operations Research, 36(5), pp. 1393-1405 (2009).

45. Bagherinejad, J. and Niknam, A. "Solving the competitive facility location problem considering the reactions of competitor with a hybrid algorithm including tabu search and exact method", Journal of Industrial Engineering International, 14(1), pp. 171-183 (2018).

46. Fernández, J., Boglárka, G., Redondo, J.L., et al. "The probabilistic customer's choice rule with a threshold attraction value: Effect on the location of competitive facilities in the plane", Computers \& Operations Research, 101, pp. 234-249 (Jan. 2019).

47. Aboolian, R., Berman, O., and Krass, D. "Optimizing pricing and location decisions for competitive service facilities charging uniform price", Journal of the Operational Research Society, 59(11), pp. 15061519 (2008).

48. Fernández, J., Salhi, S., and Boglárka, G. "Location equilibria for a continuous competitive facility location problem under delivered pricing", Computers \& Operations Research, 41, pp. 185-195 (2014).

49. Fischer, K. "Sequential discrete p-facility models for competitive location planning", Annals of Operations Research, 111(1-4), pp. 253-270 (2002).

50. Pérez, M.D.G., Hernández, P.F., and Pelegrín, B.P. "On price competition in location-price models with spatially separated markets", Top, 12(2), pp. 351-374 (2004).

51. Panin, A.A., Pashchenko, M.G., and Plyasunov, A.V. "Bilevel competitive facility location and pricing problems", Automation and Remote Control, 75(4), pp. 715-727 (2014).

52. Pelegrín, B., Fernández, P., Pérez, M.D.G., et al. "On the location of new facilities for chain expansion under delivered pricing", Omega, 40(2), pp. 149-158 (2012).

53. Rohaninejad, M., Navidi, H., Nouri, B.V., et al. "A new approach to cooperative competition in facility 
location problems: Mathematical formulations and an approximation algorithm", Computers \& Operations Research, 83, pp. 45-53 (2017).

54. Meagher, K.J. and Zauner, K.G. "Product differentiation and location decisions under demand uncertainty", Journal of Economic Theory, 117(2), pp. 201216 (2004).

55. Meagher, K.J. "Optimal product variety in a Hotelling model", Economics Letters, 117(1), pp. 71-73 (2012).

56. Kress, D. and Pesch, E. "Competitive location and pricing on networks with random utilities", Networks and Spatial Economics, 16(3), pp. 837-863 (2016).

57. Konur, D. and Geunes, J. "Competitive multi-facility location games with non-identical firms and convex traffic congestion costs", Transportation Research Part E: Logistics and Transportation Review, 48(1), pp. 373-385 (2012).

58. Kwasnica, A.M. and Stavrulaki, E. "Competitive location and capacity decisions for firms serving timesensitive customers", Naval Research Logistics (NRL), 55(7), pp. 704-721 (2008).

59. Zhang, L. and Rushton, G. "Optimizing the size and locations of facilities in competitive multi-site service systems", Computers \& Operations Research, 35(2), pp. 327-338 (2008).

60. Bozkaya, B., Yanik, S., and Balcisoy, S. "A GIS-based optimization framework for competitive multi-facility location-routing problem", Networks and Spatial Economics, 10(3), pp. 297-320 (2010).

61. Lancaster, K. "The economics of product variety: A survey", Marketing Science, 9(3), pp. 189-206 (1990).

62. Rhim, H., Ho, T.H., and Karmarkar, U.S. "Competitive location, production, and market selection", European Journal of Operational Research, $149(1)$, pp. 211-228 (2003).

63. Zhang, R. "Product market competition, competitive strategy, and analyst coverage", Review of Quantitative Finance and Accounting, 50(1), pp. 239-260 (2018).

64. Brander, J.A. and Eaton, J. "Product line rivalry", The American Economic Review, 74(3), pp. 323-334 (1984).

65. Economides, N. "Minimal and maximal product differentiation in Hotelling's duopoly", Economics Letters, 21(1), pp. 67-71 (1986).

66. Beresnev, V.L. and Suslov, V.I. "A mathematical model of market competition", Journal of Applied and Industrial Mathematics, 4(2), pp. 147-157 (2010).

67. Sadjadi, S.J., Ashtiani, M.G., Ramezanian, R., et al. "A firefly algorithm for solving competitive locationdesign problem: a case study", Journal of Industrial Engineering International, 12(4), pp. 517-527 (2016).
68. Hansen, P., De Aragão, M.V.P., and Ribeiro, C.C. "Boolean query optimization and the 0-1 hyperbolic sum problem", Annals of Mathematics and Artificial Intelligence, 1(1-4), pp. 97-109 (1990).

69. Benati, S. and Hansen, P. "The maximum capture problem with random utilities: Problem formulation and algorithms", European Journal of Operational Research, 143(3), pp. 518-530 (2002).

70. Benati, S. "The maximum capture problem with heterogeneous customers", Computers \& Operations Research, 26(14), pp. 1351-1367 (1999).

71. Yang, X.S. "Firefly algorithms for multimodal optimization", In Stochastic Algorithms: Foundations and Applications, pp. 169-178, Springer Berlin Heidelberg (2009).

72. Yang, X.S. "Firefly algorithms for multimodal optimization", In International Symposium on Stochastic Algorithms, pp. 169-178, Springer Berlin Heidelberg (2009, October).

73. Yang, X.S., Nature-Inspired Metaheuristic Algorithms, Luniver press (2010).

74. Sayadi, M., Ramezanian, R., and Ghaffari-Nasab, N. "A discrete firefly meta-heuristic with local search for makespan minimization in permutation flow shop scheduling problems", International Journal of Industrial Engineering Computations, 1(1), pp. 1-10 (2010).

75. Parasuraman, A., Zeithaml, V.A., and Berry, L.L. "Servqual: A multiple-item scale for measuring consumer perc", Journal of Retailing, 64(1), p. 12 (1988).

76. Mostaghel, R. and Albadvi, A. "A cross-cultural comparison of service quality prioritization", Scientia Iranica, Transactions E, Industrial Engineering, 16(1), p. 65 (2009).

\section{Biographies}

Seyed Jafar Sadjadi finished his $\mathrm{PhD}$ at the University of Waterloo, Canada. His research interest is focused on solving different classes of optimization problems in industrial engineering areas, such as supply chain management, portfolio optimization, optimal pricing, etc. He has been serving at Iran University of Science and Technology since 2001.

Milad Gorji Ashtiani has studied in the field of Industrial Engineering at Iran University of Science and Technology. His PhD research focuses on the modeling and analysis of the facilities location in a competitive environment. His research interests include operations research, location theory, project planning, and supply chain management.

Ahmad Makui is a Professor of Industrial Engineering at Iran University of Science and Technology. He received his MS degree in 1991 and $\mathrm{PhD}$ degree in 1994 in Industrial Engineering from Iran University of 
Science and Technology. He lectures in the fields of scheduling, project and product planning and control, and MCDM. He has published three books in Persian and more than 100 national and international papers on scheduling and other subjects. His main research interests consist of scheduling, MCDM, and supply chain management.
Reza Ramezanian is an Assistant Professor of Industrial Engineering at K. N. Toosi University of Technology. He received $\mathrm{BS}$, MS, and $\mathrm{PhD}$ degrees from Iran University of Science and Technology, Tehran, Iran. His research interests include operations research, production planning, dynamic lot-sizing, scheduling, and deterministic and stochastic optimization. 